\title{
Positive Psychology in Neurodiversity: An Evaluation of Character Strengths and Humour-based Intervention for Wellbeing and Depression in Autistic Adults
}

\author{
Alicja Sabina Nocon ${ }^{1}$, Amanda Roestorf, $\mathrm{PhD}^{1}$, and Luz María Gutiérrez Menéndez ${ }^{1}$ \\ ${ }^{1}$ Affiliation not available
}

February 15, 2022

\begin{abstract}
\end{abstract}
\section{Background}

The positive psychology and neurodiversity movements both aim to promote and improve wellbeing through strengths-based approaches. However, little is known about how positive psychology can support the wellbeing of autistic people. The present used character strengths profiles and a humour-based positive psychology exercise as potential tools to improve the life satisfaction and mental health of autistic adults. To our knowledge, this is first study to use these methods as possible ways of improving the wellbeing of autistic adults in the community in the UK.

\section{Method}

Forty-seven autistic adults completed self-rated standardised questionnaires about their character strengths, life satisfaction, happiness and depressive symptoms. Additionally, 22 participants from this group completed the three funny things exercise for one week, and follow-up questionnaires about happiness and depressive symptoms.

\section{Results}

Character strengths most frequently reported by autistic adults were Honesty, Appreciation of Beauty and Excellence, Love of Learning, Fairness and Kindness. Higher levels of life satisfaction were associated with character strengths of Hope, Honesty, Gratitude, Forgiveness and Zest (Vitality). Participants reported fewer depressive symptoms and similar levels of happiness after completing the three funny things exercise.

\section{Conclusions}

The most frequent character strengths were consistent with autistic traits reported in the wider body of autism literature, such as intense interests and strong attention to detail. The present study provides, for the first time, evidence for strengths- and humour-based interventions that can effectively be used in a community setting to promote positive wellbeing outcomes in autistic adults.

\section{Hosted file}

Nocon_Roestorf_Guti \selectlanguage\{ngerman\}érrez Menéndez_2022-02-15_submitted.pdf available at https://authorea.com/users/430174/articles/556532-positive-psychology-inneurodiversity-an-evaluation-of-character-strengths-and-humour-based-intervention-forwellbeing-and-depression-in-autistic-adults 